\title{
DRESS sendromlu 11 olgunun klinik özelliklerinin incelenmesi
}

\author{
Evaluation of clinical features of 11 cases with DRESS syndrome
}

\author{
Selma Emre, Gülșen Akoğlu, Ahmet Metin*, Duriye Deniz Demirseren, Gözde Kurtoğlu \\ Ankara Atatürk Eğitim ve Araștırma Hastanesi, Dermatoloji Kliniği, Ankara, Türkiye \\ *Yıldırım Beyazıt Üniversitesi Tıp Fakültesi, Atatürk Eğitim ve Araștırma Hastanesi, Dermatoloji Kliniği, Ankara, Türkiye
}

\section{Özet}

Amaç: DRESS (Drug Rash with Eoshinophilia and Systemic Symptoms) sendromu, ilaçlarla tetiklenen, kutanöz, hematolojik ve solid organ tutulumlarının eşlik ettiği şiddetli bir reaksiyondur. Tedavisinde spesifik yaklaşımların gerekmesi ve yüksek mortalite oranları nedeniyle sendromun erken tanınması çok önemlidir. DRESS sendromu ile ilgili ülkemizde az sayıda olgu bildirimi dışında tanımlayııı bir çalışma bulunmamaktadır. Bu çalışmada merkezimizde DRESS sendromu tanısı alan hastaların klinik özelliklerinin incelenmesi amaçlandı.

Gereç ve Yöntem: Kliniğimizde DRESS sendromu veya ilaç erüpsiyonu tanısı ile yatarak tedavi edilen hastaların dosyaları retrospektif olarak incelendi. RegiSCAR grubu tarafından oluşturulan skorlama sistemine göre hastaların mevcut bulguları puanlandırılarak, kesin, olası ve muhtemel DRESS sendromlu hastalar belirlendi. Hastaların klinik özellikleri, laboratuvar bulguları ve hastalık için etyolojik faktörleri incelendi. Bulgular: Çalışmaya 7'si erkek, 4'ü kadın olmak üzere toplam 11 DRESS sendromu tanısı alan hasta dahil edildi. Dört hasta kesin DRESS, 7 hasta ise muhtemel DRESS olarak tanımlandı. Hastaların hepsinde sorumlu ilaç aromatik antikonvülzanlardı. DRESS nedeni olan ilaçlar 5 hastada fenitoin, 3 hastada karbamezepin, 3 hastada lamotrijindi. Hastaların tamamında kutanöz tutulum ve hematolojik anormallikler mevcuttu. Tespit edilen diğer bulgular sıklık sırasına göre ateş, karaciğer fonksiyonlarında bozulma, lenfadenopati, böbrek tutulumu ve pnömoniydi. Sorumlu ilacın kesilmesi ve sistemik kortikosteroid tedavisi ile tüm hastaların bulgularında tam düzelme sağlandı.

Sonuç: DRESS sendromlu hastalar çeşitli klinik görünümlerle karşımıza çıkabilir. Sendromun tanınmasında belirti ve bulguların temel teşkil etmesi nedeniyle hastaların klinik özelliklerinin iyi bilinmesi DRESS sendromunun erken tanınmasına, dolayısıly mortalite ve morbiditenin azaltılmasına katkıda bulunmaktadır. (Türkderm 2013; 47: 218-22)

Anahtar Kelimeler: DRESS sendromu, ilaçla indüklenen hipersensitivite sendromu, şiddetli kutanöz ilaç reaksiyonu

\section{Summary}

Background and Design: DRESS (Drug Rash with Eosinophilia and Systemic Symptoms) syndrome is a severe reaction induced by drugs and accompanied by cutaneous, hematologic and solid organ involvement. Since the syndrome requires specific treatments and has high mortality rates, early diagnosis is very important. In our country, any descriptive study has not been reported about patients with DRESS syndrome except for a few case presentations. Therefore, we aimed to investigate the clinical characteristics of patients with DRESS syndrome diagnosed and treated in our inpatient clinic.

Materials and Methods: The records of patients diagnosed with DRESS syndrome or drug eruption were retrospectively analyzed. Scoring system created by a RegiSCAR group was used. Patients with certain, probable and possible DRESS syndrome were identified. Clinical features, laboratory findings and etiological factors were noted.

Results: Seven males and 4 females with DRESS syndrome were enrolled. Four patients were identified as definite case and seven were probable DRESS syndrome. Aromatic anticonvulsants were the only responsible drugs (phenytoin in 5, carbamezepine in 3, lamotrigine in 3 patients). All patients had cutaneous manifestations and hematological abnormalities. Fever, liver function impairment, lymphadenopathy, renal disease and pneumonia were the clinical findings in order of frequency. Cessation of responsible drugs and treatment with systemic corticosteroids achieved full remission in all patients.

Conclusion: DRESS syndrome may present with various clinical manifestations. Because signs and symptoms form the basis for recognition of the disease, good knowledge of clinical features is important in early diagnosing DRESS syndrome and reducing mortality and morbidity. (Turkderm 2013; 47: 218-22)

Key Words: DRESS syndrome, drug-induced hypersensitivity syndrome, severe cutaneous drug reaction

Yazışma Adresi/Address for Correspondence: Dr. Selma Emre, Ankara Atatürk Eğitim ve Araştırma Hastanesi, Dermatoloji Kliniği, Ankara, Türkiye

Tel.: +90 31229125 25/3660 E-posta: dr_semre@yahoo.com Geliş Tarihi/Received: 17.01.2013 Kabul Tarihi/Accepted: 08.02.2013 


\section{Giriş}

Illaçla indüklenen hipersensitivite sendromu (Drug Induced Hypersensitivity Syndrome; DIHS) adıyla da bilinen DRESS (Drug Rash with Eoshinophilia and Systemic Symptoms) sendromu, ilaca bağlı akut bir hipersensitivite reaksiyonudur. ilk antikonvülzan ilaç olan hidantoin ve türevlerinin tedavide kullanılmaya başlanması ile 1940'larda sendromun ilk isimlendirilme girişimleri başlamıştır ${ }^{1}$. DRESS sendromunun akronim şeklindeki isimlendirilmesi ilk kez 1996'da Bacquet ve arkadaşları tarafından yapılmıştır. Akronimde bulunmasına rağmen eozinofilinin olması her zaman gerekli değildir2. DRESS sendromunun patogenezi tam olarak anlaşılamamıştır. Aromatik amin antikonvülzanların metabolitlerini detoksifiye eden epoxide hidroxilaz enziminin eksikliği veya defektif olması etyolojide sorumlu tutulan en önemli nedendir. Sorumlu ilacın detoksifikasyonundaki yetersizliğe bağlı olarak, artan reaktif metabolitlerin immunolojik reaksiyona sebep olduğu düşünülmektedir. Bazı HLA allellerine bağlı etnik predispozisyonun DRESS sendromunda etkili olduğu da öne sürülmektedir. Ayrıca, Ebstein Barr Virüsü (EBV), sitomegalovirüs (CMV), human herpes virus (HHV) 6 ve HHV 7 gibi herpesvirüslerin reaktivasyonunun reaksiyonu tetiklediği düşünülmektedir2-4.

Klinik bulgular genellikle sorumlu ilacın kullanımaya başlanmasından 2-8 hafta sonra ortaya çıkar. Sorumlu ilacın kesilmesine rağmen semptomlar devam edebilir, hatta şiddetlenebilir2. Deri belirtilerinin spektrumu çok geniştir. Sendromun kliniği tam olarak geliştiğinde, şiddetli mukokutanöz düküntüye ek olarak, ateş, lenfadenopati (LAP), hematolojik bozukluklar ve iç organ tutulumları görülebilir4,5. Farklı organ tutulumları ve deri bulgularının çeşitliliği nedeniyle DRESS sendromunun tanısı zordur2,6. Temel özellikler olan raş, ateş ve iç organ tutulumları nedeniyle, başta infeksiyonlar olmak üzere birçok hastalığı taklit edebilmektedir7. Tanıda bir fikir birliğinin sağlanması amacıyla RegiSCAR grubu tarafından DRESS sendromu için tanı kriterleri belirlenmiştir6. RegiSCAR, büyük ve çok uluslu bir kayıt sistemi ile şiddetli kutanöz ilaç reaksiyonlarının (Severe Cutaneous Adverse Reactions; SCAR) takip ve tanı kriterlerinin oluşturulması için prospektif araştırmalar yapan bir çalışma grubudur. RegiSCAR çalışma grubu tarafından potansiyel DRESS sendromu vakalarının belirlenmesi amacıyla dahil edilme kriterleri oluşturulmuştur (Tablo 1$)^{6}$.

Yaklaşık \%10-20 gibi yüksek mortalite riski taşıyan bir durum olması sebebiyle DRESS hastalarının erken fark edilmesi ve tanınması çok önemlidir4,6. DRESS sendromunun klinik bulguları Tablo 2'de özetlenmiştir. DRESS sendromu için ülkemizde az sayıda olgu bildirimi dışında tanımlayıcı bir çalışma bulunmamaktadır. Biz bu çalışmada, DRESS sendromu tanısı ile kliniğimizde yatarak tedavi edilen hastaların klinik ve laboratuvar bulgularını literatür ile karşılaştırarak ülkemizdeki DRESS sendromlu hastaların özelliklerini gözden geçirmeyi amaçladık.

\section{Gereç ve Yöntem}

Haziran 2010 ile Aralık 2012 tarihleri arasında kliniğimizde DRESS sendromu veya ilaç erüpsiyonu tanısı ile yatarak tedavi edilen hastaların dosyaları retrospektif olarak incelendi. Hastalardaki mevcut klinik ve laboratuvar bulguları açıklayacak olası etyolojik faktörler dışlandı. RegiSCAR grubunun oluşturduğu araştırmaya dahil edilme kriterleri kullanılarak potansiyel DRESS sendromu vakaları belirlendi ve çalışmaya alındı6. Hastaların klinik ve laboratuvar bulguları, ilaç öyküleri detaylı olarak gözden geçirildi. Yine RegiSCAR grubu tarafından oluşturulan skorlama sistemine göre hastaların mevcut bulguları puanlandırılarak, kesin, olası ve muhtemel DRESS vakaları belirlendi6. Bu skorlama sistemine göre final skoru <2 olanlar ilişkili değil, 2-3 puan olası DRESS, 4-5 puan muhtemel DRESS ve $>5$ puan kesin DRESS olarak kabul edildi.

\section{Bulgular}

Çalışmaya toplam 11 hasta dahil edildi. Çalışmaya alınan hastaların yedisi erkek, dördü kadındı. Hastaların yaşları 21 ile 83 (ortalama $49,4)$ arasındaydı. Hastalardan 4'ü kesin DRESS, yedisi ise muhtemel DRESS olarak tanımlandı. Sorumlu ilaç hastaların beşinde $(\% 45,5)$ fenitoin, üçünde karbamezepin $(\% 27,2)$, ve üçünde de lamotrijindi $(\% 27,2)$. Ilaç kullanımı ile hastalığın başlaması arasındaki süre 13 gün ile 8 hafta arasında (ortalama 27,2 gün) değişiyordu. Deri lezyonları 11 hastanın tamamında mevcuttu. Lezyonlar dokuz hastada morbiliform tipte (Resim 1) ve iki hastada eritrodermi tipindeydi. Mukokutanöz bulgular dört hastada gözlenirken, hastaların üçünde periorbital ve fasiyal ödem vardı (Resim 2). Hastaların temel özellikleri, klinik ve laboratuvar bulguları Tablo 3'te görülmektedir. Hastalarımızın tamamında sorumlu ilacın kesilmesi ve sistemik kortikosteroid tedavisi ile bulgular düzeldi.

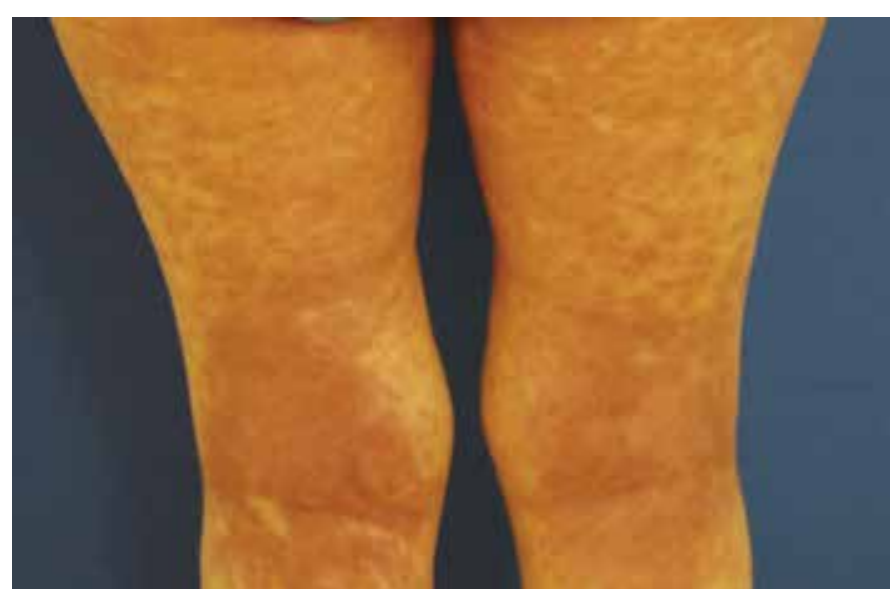

Resim 1. Otuz dokuz yaşında kadın hastanın uyluk arka yüzlerinde morbiliform lezyonlar

\section{Tablo 1. RegiSCAR grubunun belirlediği potansiyel} DRESS vakası kabul edilme kriterleri

Hastanede yatarak tedavi gereksinimi

Reaksiyona sebep olabilecek şüpheli ilaç kullanımının varlığ

Akut deri döküntüsü

$38^{\circ} \mathrm{C}^{\prime}$ nin üzerinde ateş

En az 2 alanda LAP

En az bir iç organ tutulumu

Kan bulguları

Lenfosit sayısının normalden az veya fazla olması

Eozinofil yüksekliği (sayı veya yüzde olarak)

Trombosit sayısının normal değerlerin altında olması

İlk iki bulgu dışındaki bulgulardan 3 veya daha fazlasının varlığı gereklidir (6). 
Tablo 2. DRESS sendromunun klinik bulguları

\begin{tabular}{|l|l|}
\hline Deri bulguları & $\begin{array}{l}\text { Ürtikeryal morbiliform lezyonlar, vezikül, bül, püstül, keilit, purpura, hedef benzeri lezyonlar, eritroderma, } \\
\text { TEN-DRESS overlap } \\
\text { Fasiyal ve periorbital ödem } \\
\text { Lenfoma benzeri infiltre lezyonlar }\end{array}$ \\
\hline Ateş & $38^{\circ} \mathrm{C}$ ve üzeri \\
\hline LAP & Lokalize veya generalize olabilir \\
\hline Hematolojik anormallikler & Lökositoz, eozinofili, atipik lenfositler, lenfopeni, lökopeni veya lenfositoz, nadiren hemofagositik sendrom \\
\hline İ̧ organ tutulumu & $\begin{array}{l}\text { Hepatit, böbrek tutulumu, interstisyel pnömoni, myokardit, farenjit, menenjit ve ensefalit, gastrointestinal } \\
\text { sistem kanaması }\end{array}$ \\
\hline Viral infeksiyonların reaktivasyonu & HHV 6, HHV 7, EBV, CMV \\
\hline
\end{tabular}

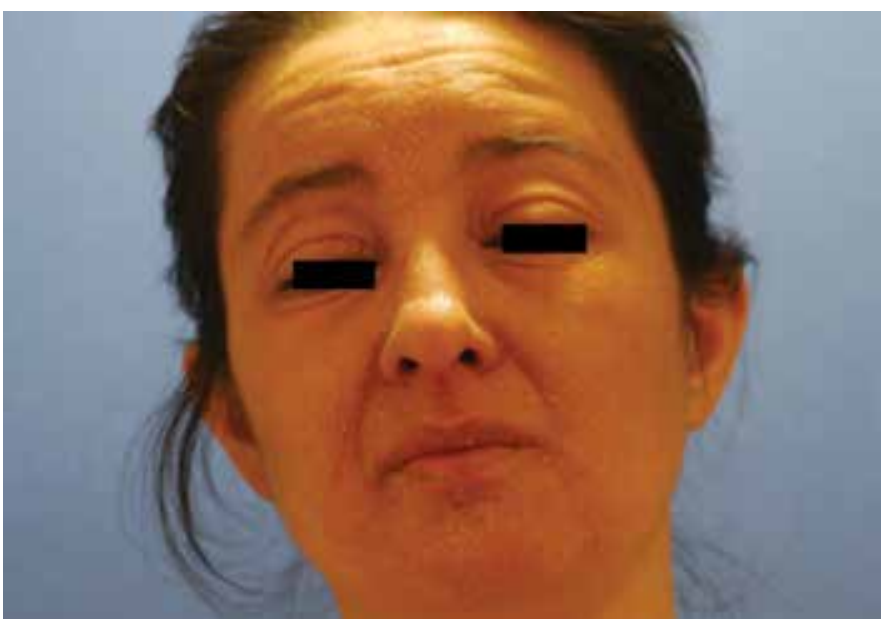

Resim 2. Yüzde periorbital ödem, eritem ve deskuamasyonlar

\section{Tartışma}

DRESS sendromunun insidansı tam olarak bilinmemektedir. Ancak, sık neden olan ilaçlardan antikonvülzanlar ve sulfonamidler için 100010.000 ilaç maruziyetinde bir olduğu tahmin edilmektedir. DRESS sendromu nedeni olarak 50'den fazla ilaç bildirilmiş olmakla birlikte en sık neden olan ilaçlar, aromatik antikonvülzanlar, allopurinol ve sulfonamidlerdir4,8. Bu çalışmada takip edilen hastaların tamamında sorumlu ilaç aromatik antikonvülzanlardı. Bizim hastalarımıza benzer şekilde Brezilya'da da fenitoinin en sık sorumlu ilaç olduğu bildirilmiştir5. Yang ve ark. ${ }^{9}$ antikonvülzan ilaçlardan karbamezepin ve fenitoinin tüm DRESS sendromu vakalarının \%43,6'sından sorumlu olduğunu buna karşılık valproik asit ve topiramata bağlı şiddetli kutanöz ilaç reaksiyonuna rastlanmadığını bildirdiler ${ }^{9}$. Valproik asit lamotrijinin metabolizmasını inhibe eder. Birlikte kullanıldığında lamotrijine bağı reaksiyon riskini artıır2,4. Bizim hasta serimizde bir hastada DRESS sendromu lamotrijin ve valproik asitin birlikte kullanımı sonucu ortaya çıkmıştı. Diğer ilaç reaksiyonlarında olduğu gibi DRESS sendromu etyolojisinde de dünyanın farklı coğrafi bölgelerinde farklı ilaçlar ön plana çıkmaktadır. Taiwan'da yapılan çalışmalarda en sık sorumlu olan ilacın DRESS hastalarının yaklaşık \%31-37'sinde etkili olan allopurinol olduğu bildirilmiş̧ir ${ }^{10,11}$. Ülkemizde de allopurinol kullanımına bağlı DRESS vakası bildirilmiştir12. Ülkemizde ayrıca karbamezepin, lamotrijin ve opipramol kullanımı ile ilişkili DRESS vakaları da tek olgular halinde bildirilmiştir13-15. Son zamanlarda
DRESS etyolojisinde suçlanan ilaçlardan biri de vankomisindir. Özellikle parenteral vankomisin kullanımının sık olduğu yatarak tedavi gören hastalar arasında vankomisine bağlı DRESS vakalarının bildirimi de giderek artmaktadır 16,17 .

Bizim takip ettiğimiz hastalar arasında en sık bulgu 11 hastanın tamamında gözlenen kutanöz erüpsiyondu. Kutanöz erüpsiyon 9 hastada generalize morbiliform erüpsiyon şeklinde, 2 hastada eritrodermi tipindeydi. Lezyonlar eritemli maküller olarak başlayıp giderek büyüyerek düzensiz sınırlı geniş yamalar oluşturuyordu. Hastalarımızdan dördünde $(\% 32,7)$ oral mukoza tutulumu vardı. Son zamanlarda Cacoub ve ark. ${ }^{2}$ tarafından yapılan literatür taramasında kutanöz erüpsiyonun, hastaların \%97'sinde, mukoza tutulumunun ise \%60'ında bulunduğu bildirilmiştir. Chiou ve ark. ${ }^{10}$ deri tutulumunu $\% 80$, mukoza tutulumunu \%61 oranında gördüklerini bildirdiler. Bizim tüm hastalarımızda kutanöz erüpsiyonun olması yalnızca dermatoloji kliniğinde yatarak tedavi gören hastaları değerlendirmemiz ile açıklanabilir. Hastalarımızdaki mukoza lezyonlarının hepsi oral mukozadaydı ve tedaviye cevapları iyiydi. Üç hastada fasiyal ve/veya periorbital ödem gözlendi. Önceki çalışmalarda da fasiyal ve periorbital sıklığı \%25-39 arasında bildirilmiştir2,4. Walsh ve ark. ${ }^{8}$ deri lezyonlarının tipi ve prognoz arasındaki ilişkiyi araştırdıkları çalışmalarında, eritema multiforme benzeri, atipik hedef tarzında lezyonların olduğu hastalarda karaciğer tutulumunun anlamlı olarak daha şiddetli ve kötü prognozlu olduğunu bildirdiler. Aynı çalışmada diğer tiplerdeki deri lezyonlarının prognostik bir özelliği olmadığını bildirdiler.

Çalışmamızdaki hastaların tamamında en az bir hematolojik anormallik mevcuttu. Bu anormalliklerden en sık rastladığımız 11 hastanın yedisinde $(\% 63,6)$ bulunan eozinofiliydi. Önceki yayınlarda hematolojik bozuklukların sıklığı \%23-50 arasında bildirilmişti4,10,18. Bizim hastalarımızdaki sonuçlara benzer şekilde literatürde de eozinofili en sık hematolojik bozukluk olarak bildirilmiştir 1,8. Bizim hasta serimizde ateş en sık görülen diğer bir bulguydu. Onbir hastanın 10'unda $(\% 90,9)$ ateş tespit edildi. Literatürde vakaların \%90-100'ünde ateş bildirilmiştir ve bizim sonuçlarımız literatür ile benzerdi2.

En sık rastladığımız iç organ tutulumu karaciğer fonksiyon bozukluğuydu. Bu çalışmada hastaların 10'unda $(\% 90,9)$ karaciğer enzimlerinde normalin en az 5 katı yükselme mevcuttu. Karaciğer DRESS sendromunda en fazla etkilenen iç organdır. Sendromun erken tanınması ve sorumlu ilacın erken kesilmesi ile karaciğer hasarı sınırlandırılabilir4. Biz hastalarımızda reaksiyonun tanınıp tedaviye başlanmasından önceki sürede karaciğer enzimlerinde kısa sürede hızlı bir yükselme olduğunu gözlemledik. Bu yükselme günler, hatta saatler 


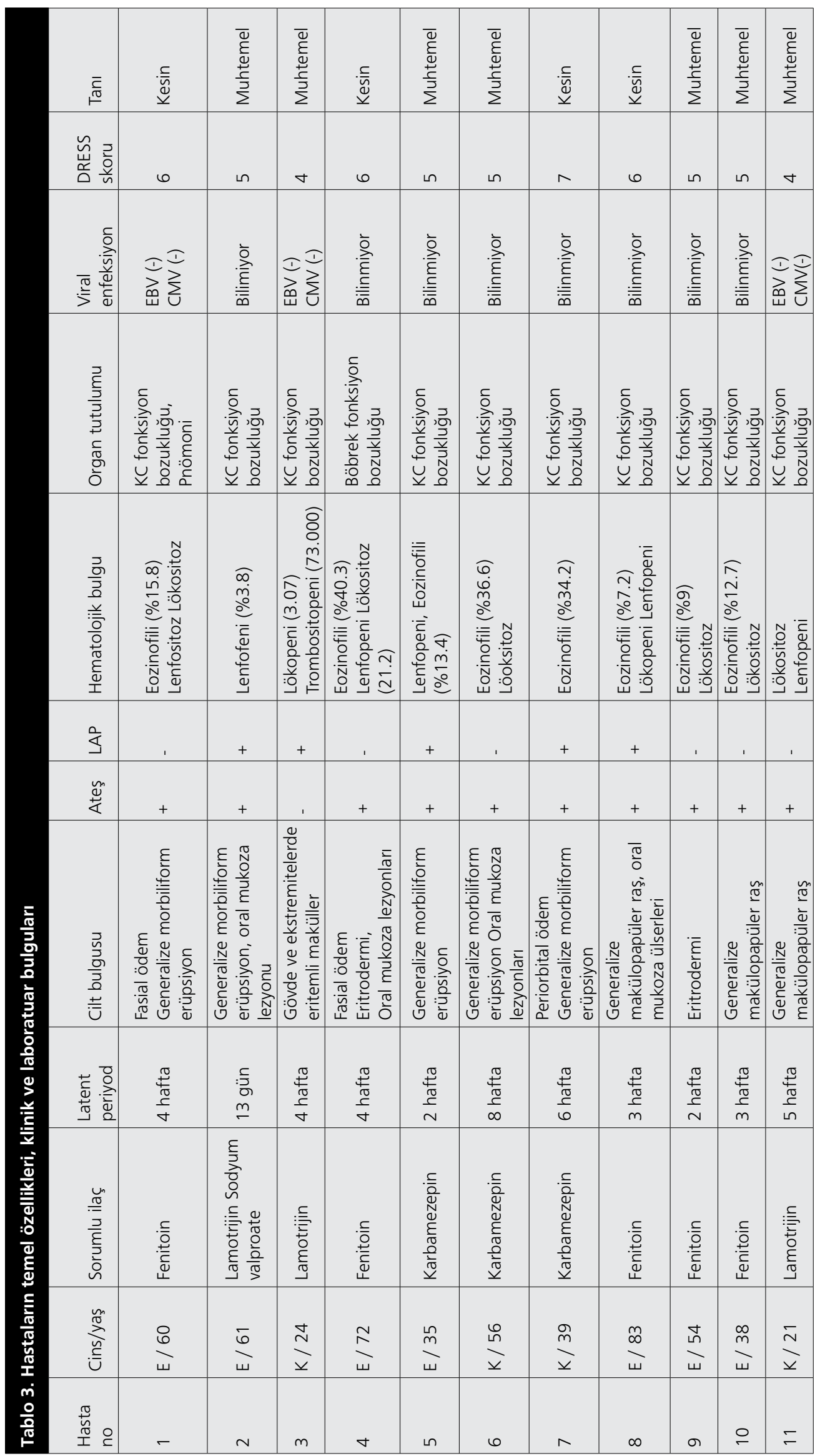


içerisinde tespit edilebilir düzeydeydi. Sistemik kortikosteroid tedavisi ile de hızlı bir düzelme tespit ettik. Bazen, sorumlu ilacın kesilmesine rağmen klinik bulgularda kötüleşme olması DRESS için karakteristik bir özelliktir ${ }^{19}$. Bizim hasta serimizde bir hastamızda klinik ve laboratuvar bulgular düzeldikten ve hasta taburcu edildikten iki hafta sonra karaciğer fonksiyonlarında ve hematolojik parametrelerde bozulma ortaya çıktı. Bu durumun kortikosteroid tedavisinin erken kesilmesine bağlı olduğunu düşünüyoruz.

Bir hastamızda böbrek fonksiyonlarında bozulma tespit edildi. SIVI elektrolit dengesinin sağlanması ve sistemik kortikosteroid tedavisi ile böbrek fonksiyonları günler içerisinde düzeldi. Chen ve ark. ${ }^{11}$ allopurinolün neden olduğu DRESS vakalarında böbrek tutulumunun daha sık olduğunu bildirdiler. Bizim hastalarımızda allopurinol öyküsü yoktu; bu nedenle bizim vakalarımızdaki böbrek tutulumu oran Taiwan'da bildirilenlerden düşüktü10,11. LAP, DRESS sendromu için tan kriterlerinden biri olup, sık görülen bir belirtidir. Bizim hastalarımızdan beşinde $(\% 45,4)$ LAP tespit edildi. Bu oranlar literatürle uyumlu idi2,10. DRESS sendromu için cinsiyet açısından farklılık olmadığ bilinmektedir4,10. Bizim hasta serimizde erkek hastaların sayısı $(\% 63,6)$ kadınlardan $(\% 36,4)$ fazlaydı. Bizim hastalarımıza benzer şekilde erkek hasta sayısının fazla olduğu çalışmalar yanında kadın hasta sayısının fazla olduğu çalışmalar da bildirilmiştir2,5,8. Bu farklılığın nedeni bildirilen hasta sayılarının az olması ve toplumsal farklılıklar olabilir. DRESS sendromlu hastalarda mortalite oranları \%10-20 olarak bildirilmiştir2,5,8. Bizim hastalarımızın hiçbirinde mortalite gözlenmedi. Mortaliteyi azaltan en önemli nedenlerden biri reaksiyonun erken tanı ve tedavisinin sağlanmasıdır. Diğer önemli bir neden ise sorumlu ilaçların prognozu belirlemede etkili olması olabilir. Bizım hastalarımızın tümünde sorumlu ilaçlar aromatik antikonvülzanlardı. Aromatik antikonvülzanların neden olduğu DRESS vakalarında prognoz nispeten daha iyi gibi görünmektedir. Yang ve ark. ${ }^{9}$ aromatik antikonvülzanlara bağlı DRESS vakalarında mortalitenin \%7,7 olduğunu bildirdiler. Chen ve ark.20 ise allopurinole bağlı DRESS vakalarında mortalitenin en yüksek olduğunu bildirdiler. Bizim hastalarımızın etyolojisinde bulunmayan minosiklin ve dapson kullanımı ile ilişkili DRESS vakalarının da daha kötü prognozlu olduğu bildirilmiştir ${ }^{4}$. Ayrıca eşlik eden herpes virus reaktivasyonlarının da kötü prognozda etkili olduğu düşünülmektedir. HHV 6 ve CMV reaktivasyonu ile ilgili olan sarılık ve hepatitin kötü prognoz ile ilişkili olduğu bildirilmiştir21,22. Bizim çalışmamızın en önemli kısıtlayıcı yönü hastalarda virus reaktivasyonunun olup olmadığının tam olarak bilinememesidir. HHV 6 testleri ülkemizde çoğu hastanede olduğu gibi bizim hastanemizde de yapılamamaktadır. Ayrıca hastalığın aktif döneminde hastalarımızdan yalnızca üçünün CMV ve EBV serolojik tetkikleri yapılmıştı. Serolojik testlerin yapıldığı 3 hastada da virüs reaktivasyonu yoktu.

Klinik özelliklerinin geniş bir yelpazede olması ve latent periyodunun uzun olması nedeniyle DRESS sendromunun tanısında sıklıkla gecikmeler olur1,4. Aynı grup ilaçların tekrar kullanımı ile fatal seyredebilmesi hastalığın erken tanısını daha önemli hale getirmektedir. Tanı konulan ve takip edilen hastaların sayısının artması ve bu bilgilerin paylaşılması ile yeni DRESS vakalarının daha erken dönemde tanınacağını ve akılda kalacağını düşünüyoruz. Hastalığın erken tanısı ve sorumlu ilacın, reaksiyonun erken döneminde kesilmesi bu vakalarda mortalite ve morbiditenin azalmasına katkıda bulunacaktır.

\section{Kaynaklar}

1. Walsh SA, Creamer D: Drug reaction with eosinophilia and systemic symptoms (DRESS): a clinical update and review of current thinking. Clin Exp Dermatol 2010;36:6-11

2. Cacoub P, Musette $P$, Descamps $V$, et al: The DRESS syndrome: A literature review. Am J Med 2011:124:588-597.

3. Bouvresse $\mathrm{S}$, Valeyrie-Allanore $\mathrm{L}$, Ortonne $\mathrm{N}$, et al: Toxic epidermal necrolysis, DRESS, AGEP: Do overlap cases exist? Orphanet J Rare Dis 2012; 2012;7:72 doi: 10.1186/1750-1172-7-72

4. Criado PR, Criado RFJ, Avancini JM, Santi CG: Drug reaction with eosinophilia and systemic symptoms (DRESS)/ drug-induced hypersensitivity syndrome (DIHS): a review of current concepts. An Bras Dermatol 2012;87:435-49.

5. Botelho LF, Higashi VS, Padilha MH, Enokihara MM, Porro AM: DRESS: clinicopathological features of 10 cases from an University Hospital in São Paulo. An Bras Dermatol 2012;87:703-7.

6. Kardaun SH, Sidoroff A, Valeyrie-Allanore L, et al: Variability in the clinical pattern of cutaneous side-effects of drugs with systemic symptoms: does a DRESS syndrome really exist? Br J Dermatol 2007;156:609-11.

7. Ferahbaş A, Özyurt K. Antikonvülzan hipersensitivite sendromu. Erciyes Tıp Dergisi 2002;24:107-11.

8. Walsh S, Diaz-Cano S, Higgins E, et al: Drug Reaction with Eosinophilia and Systemic Symptoms (DRESS): Is cutaneous phenotype a prognostic marker for outcome? A review of clinicopathological features of 27 cases. $\mathrm{Br} \mathrm{J}$ Dermatol 2012 Oct 3. doi: 10.1111/bjd.12081.

9. Yang CY, Dao RL, Lee TJ, et al: Severe cutaneous adverse reactions to antiepileptic drugs in Asians. Neurology 2011;77:2025-33.

10. Chiou CC, Yang LC, Hung SI, et al: Clinicopathological features and prognosis of drug rash with eosinophilia and systemic symptoms: a study of 30 cases in Taiwan. J Eur Acad Dedmatol Verenol 2008;22:1044-9.

11. Chen YC, Chiu HC, Chu CY: Drug Reaction With Eosinophilia and Systemic Symptoms:A Retrospective Study of 60 Cases. Arch Dermatol 2010;146:1373-9.

12. Yaylacı S, Demir MV, Temiz T, Tamer A, Uslan MI: Allopurinol-induced DRESS syndrome. Indian J Pharmacol 2012:44:412-4.

13. Durusoy Ç, Doğan C, Aydın Ö. Lamotrigine Bağlı Antikonvülzan Hipersensitivite Sendromu. Yeni Tıp Dergisi 2010;27:193-5.

14. Karadağ AS, Güngör E, Gönültaş M, Ekșioğlu M. Karbamazepine Bağlı Hipersensitivite Sendromu. Turkiye Klinikleri Dermatol 2004;14:166-71.

15. Uçak-Bakkal S, Koçak-Tufan Z, Bulut C, Boyraz S, Vahaboğlu G. Sepsisi taklit eden bir DRESS sendromu olgusu. Klimik Dergisi 2011;24:132-4.

16. O'Meara P, Borici-Mazi R, Morton AR, Ellis AK: DRESS with delayed onset acute interstitial nephritis and profound refractory eosinophilia secondary t vancomycin. Allergy Asthma Clin Immunol 2011;7:16. doi:10.1186/17101492-7-16

17. Blumenthal KG, Patil SU, Long AA: The importance of vancomycin drug rash with eosinophilia and systemic symptoms (dress) syndrome. Allergy Asthma Proc 2012;33:165-71

18. Criado PR, Avancini J, Santi CG, et al: Drug reaction with eosinophilia and systemic symptoms (DRESS): a complex interaction of drugs, viruses and the immune system. Isr Med Assoc J 2012;14:577-82.

19. Moling O, Tappeiner L, Piccin A, et al: Treatment of DIHS/DRESS syndrome with combined $\mathrm{N}$-acetylcysteine, prednisone and valganciclovir-a hypothesis. Med Sci Monit 2012;18:57-62.

20. Chen YC, Chang CY, Cho YT, Chiu HC, Chu CY: Long-term sequelae of drug reaction with eosinophilia and systemic symptoms: a retrospective cohort study from Taiwan. J Am Acad Dermatol 2012. doi:10.1016/j. jaad.2012.08.009

21. Asano $Y$, Kagawa $H$, Kano $Y$, Shiohara T: Cytomegalovirus disease during severe drug eruptions: report of 2 cases and retrospective study of 18 patients with drug-induced hypersensitivity syndrome. Arch Dermatol 2009;145:1030-6

22. Gentile I, Talamo M, Borgia G: Is the drug-induced hypersensitivity syndrome (DIHS) due to human herpesvirus 6 infection or to allergy-mediated viral reactivation? Report of a case and literature review. BMC Infect Dis 2010;10:49 